\title{
Contradictory Aspects of Job Searching in the COVID-19 Pandemic: Relationships between Perceived Socioeconomic Constraints, Work Volition, and the Meaning of Work
}

\author{
Pilhyoun Yoon ${ }^{1}$ (D) and Juhee Hahn ${ }^{2, *}$ \\ 1 Department of Secretary, Inha Technical College, Incheon 22212, Korea; yoonph@inhatc.ac.kr \\ 2 College of Business and Economics, Chung Ang University, Seoul 06974, Korea \\ * Correspondence: jhan@cau.ac.kr
}

check for

updates

Citation: Yoon, P.; Hahn, J.

Contradictory Aspects of Job

Searching in the COVID-19 Pandemic:

Relationships between Perceived

Socioeconomic Constraints, Work

Volition, and the Meaning of Work.

Sustainability 2021, 13, 1012. https://

doi.org/10.3390/su13031012

Received: 29 December 2020

Accepted: 17 January 2021

Published: 20 January 2021

Publisher's Note: MDPI stays neutral with regard to jurisdictional claims in published maps and institutional affiliations.

Copyright: (c) 2021 by the authors. Licensee MDPI, Basel, Switzerland. This article is an open access article distributed under the terms and conditions of the Creative Commons Attribution (CC BY) license (https:// creativecommons.org/licenses/by/ $4.0 /)$.

\begin{abstract}
The COVID-19 pandemic is changing many aspects of our lives. The hiring and job searching situation is no exception. This study investigated somewhat contradictory aspects of selfdetermination and circumscription and compromise in the context of job searching and recruitment in South Korea's COVID-19 pandemic. Specifically, this study aimed to examine the effects of variables that control work volition, and the ways in which work volition is related to perceived socioeconomic constraints and the meaning of work, in female college students looking for a job in South Korea. Furthermore, we explored the implications for job searching and corporate personnel management in the COVID-19 pandemic. As a result, this study intended to contribute theoretically and practically to self-determination, and circumscription and compromise theory, and to suggest future research directions.
\end{abstract}

Keywords: self-determination; circumscription and compromise theory; socioeconomic constraints; work volition; meaning of work

\section{Introduction}

Even in the COVID-19 pandemic, many people are looking for work. The situation we are facing now has a lot of influence on the meaning of work [1]. The meaning of work is an important research topic in the field of personnel management in almost all places [2], and especially in South Korea [3,4]. In addition, it is an important issue for job seekers and companies' personnel management [5]. There are many reasons why a person wants to work. From the job seeker's psychological point of view, the meaning of work is linked to exploring future growth opportunities and achieving happiness and higher aspirations through personal self-realization. Therefore, finding an answer to the meaning of work becomes an important problem for individuals [6].

On the other hand, even from the company's personnel management point of view, the meaning of work is an important issue during the hiring stage. Job applicants should intend to perform their duties proficiently, as those who value what they do, and who want to be rewarded for their work, have a positive effect on the company's performance $[7,8]$. Therefore, companies set their benchmarks and check the level of the applicant's values in the context of the companies' values by means of personal and aptitude tests, document screening, and interviews. If the applicant's preparation is insufficient or his or her answers are unclear during the recruitment process, the company may consider the applicant as unauthentic. However, problems with job applicants' inconsistencies are not the only ones that occur in the hiring process. According to a survey of 733 job seekers in 2019 by a South Korean employment information company, one in five job applicants gave up after the final phase, and the main reasons were unsatisfactory salary, unsatisfactory welfare, and socioeconomic constraints [9]. Young people's awareness of socioeconomic constraints in the context of the COVID-19 outbreak shows that they were in the high-risk category 
in times of economic crisis. With a sample of 30,383 students from 62 countries, students were mainly concerned about issues to do with their future professional career and studies, and experienced boredom, anxiety, and frustration [10]. The COVID-19 outbreak and consequences for the level of the economy have increased the uncertainty and instability experienced by young people [11].

The current COVID-19 pandemic situation threatens social and economic sustainability [12]. In this context, the first research question raised in this study is as follows: "Does the socioeconomic constraints perceived by job seekers have a negative effect on the meaning of work in the COVID-19 pandemic situation? In this relationship, does work volition have a significant positive mediating effect?" From the job seeker's point of view, there are two approaches that emphasize the meaning of work. The first is to search for the meaning of work as a standard for job selection, focusing on specific values or types of meaning that individuals consider important, such as growth opportunities and interests. The second is to search for the meaningful work as a standard for job selection considering the degree of importance that an individual places on work [13]. In the background of this approach, becoming interested in the implications of work in the process of job selection leads job seekers to understand the causes of work. In addition, it can help them choose jobs without regrets in the long term [14].

However, Blustein's [15] study highlights the need to first consider the socioeconomic constraints that job seekers perceive in meaning-oriented career choices. Meanwhile, the COVID-19 pandemic situation is more likely to awaken the socioeconomic constraints of job seekers [16]. For example, while Central Europe took lockdown restrictions, many jobs were severely affected. According to a survey from France and the United States, the gap between the rich and the poor has widened during the lockdown restrictions $[17,18]$. So, people who are aware of socioeconomic constraints often have unable access to social resources (e.g., education), are frequently exposed to economic instability, and have an urge to meet external needs (e.g., family support). Therefore, there are cases where the freedom to choose a job that meets the essential needs pertaining to the job, such as the job's meaning, is limited. However, even if job seekers are aware of socioeconomic limitations, there is the concept of work volition-a career competency based on self-determination theory (SDT) - to cope with these limitation [19]. Even in the COVID-19 pandemic situation, work volition can be a key variable in realizing freedom of career choice.

Work volition refers to internal freedom to choose work in the absence of external influences or interference. In addition, the higher the level of work volition, the greater the possibility of job seekers having an active and rewarding attitude towards their jobs regardless of other people's perceptions [20]. According to these previous studies, even if job seekers perceived socioeconomic constraints, those who sought the meaning of work could show a higher level of work volition. According to SDT, individuals make decisions based on voluntary motivation. Therefore, even if the perceived socioeconomic constraints of job seekers have a negative effect on the pursuit of meaning of work, voluntary work volition could function positively. Thus, work volition can determine whether the pursuit of meaning of work is an important issue for job seekers.

In the COVID-19 pandemic, this study determined that it is important in the recruitment process to check job seekers' work volition from the SDT perspective. In addition, demonstrating the impact of work volition on the relationship between perceived socioeconomic constraints and the meaning of work could have meaningful implications for corporate personnel management.

Next, the second research question raised in this study is as follows: "In the first research question, do self-efficacy and academic performance have the effect of doublemoderating work volition in a negative direction?" It is about the variables deduced to adjust the level of work volition in the negative direction and the reasons for this. According to Gottfredson's [21,22] circumscription and compromise theory, job seekers realize the possibility that they will not be able to really choose the jobs they want. When faced with a choice related to one's career, a job seeker evaluates alternative options, which could be 
more realistic to achieve than the ones closely related to his or her values and the meaning of work. Job seekers give up their preferences and lower their priorities in the following order: (a) occupational interests, (b) social status, and (c) gender roles.

Even without the added pressure caused by COVID-19, college graduates in South Korea compete heavily in the labor market. Thus, it is difficult for them to choose a job or workplace based on their values, interests, and the meaning of work [23]. Above all, when college students look for a job, they tend to give up finding a job that is consistent with their sense of the meaning of work, which can be abstract, and focus on more practical and tangible factors such as social status and recognition, high level of compensation, etc. [23]. This study aims to verify the impact of self-efficacy and academic performance variables by identifying the low levels of work volition, and by exploring the variables affecting work volition from the perspective of circumscription and compromise theory. The results should provide meaningful implications for companies' personnel management. This study extends the conflicting views of SDT and circumscription and compromise theory to the problems of job searching and recruitment. Specifically, it confirms the moderating variables of work volition that appear in the relationship between perceived socioeconomic constraints and the meaning of work. In addition, it suggests implications for personnel management for companies interested in the results of this study.

\section{Theoretical Background}

\subsection{The Relationship of Variables in Terms of SDT Theory}

SDT is based on a humanist assumption that an individual can make decisions based on voluntary internal motivation [24-26]. Humanism argues that a person is an organism that exercises the best efforts for his or her growth and development, not just satisfying his or her needs for survival. Therefore, SDT considers human beings to be born with needs for growth and development, in addition to their survival needs [24]. These are general needs that exist in all human beings and can be divided into three categories: autonomy, relationships, and competence [24]. Deci and Ryan explain the autonomy, relationships, and competence that make up SDT as follows.

First, people want to be free to choose what they think and make sense for themselves, rather than being coerced or pressured by others or circumstances. This is a desire for autonomy. Next, people want to feel that they are connected to others by establishing relationships with people around them or by belonging to a specific community. This is a relationship need. According to social needs described in Maslow's hierarchy of needs theory, people want to feel a sense of belonging and stability in their communities [24,27]. Relationships are important in self-determination because the desire to maintain relationships with others is an important basis for maintaining people's intrinsic motivation [24]. Lastly, people want to be confident that they are effective by challenging or actively solving problems. This is a desire for competence. When the desire for competence is fulfilled, people feel confident in their ability to explore specific areas of life and to control the outcome of various activities [24,25].

According to SDT, these three need-based behaviors are internalized, autonomous behaviors that have a significant effect on job seeker's motivation to obtain a specific job or workplace [28]. For example, some job seekers have an opportunity to become freelancers, enabling them to enjoy the freer life they desire, despite the opposition of their parents. By doing so, these job seekers exercise their autonomy and take advantage of an opportunity to develop new skills. Job seekers may choose specific workplaces or start businesses based on their competence. By having specific jobs or entering workplaces, job seekers utilize opportunities to fulfill their desires for social belonging and relationships. However, behaviors driven by external demands, expectations, and mental pressures are controlled behaviors, which have a negative effect on psychological satisfaction $[28,29]$.

SDT explains the meaning of the main variable in this study. According to previous studies, intrinsic motivation based on self-determination plays an important role in realizing the meaning of work [30,31]. One of the key arguments of self-determination theory 
related to the meaning of work is that workers perceive their work as meaningful when they are implicitly motivated based on the integration of their work behaviors and selfconcepts [30]. Steger et al. [7] found a significant correlation between intrinsic motivation and the meaning of work. In addition, Kashdan and Steger [32] found that high levels of intrinsic motivation and specific curiosity at work lead to more frequent growth-oriented behavior and awareness of higher levels of life.

Scholars, who study the meaning of work in this way, argue that approaching work meaningfully is a realization of decent work because the meaning of work is a key result of self-determination [33]. However, not everyone has influence over his or her decisions $[33,34]$. Some argue that a meaning-oriented approach is not useful in the process of job selection. Brown and Brooks [35], researchers in the career counseling field, found that there was a discrepancy between job seeker's job values and his or her actual behavior in a professional life. In addition, the discussion of values in job counseling may be useful for self-understanding from the job seeker's point of view. However, it must be limited to the use as a recruitment tool from the company's perspective. Above all, the choice of a job or workplace is perceived as an opportunity, and there are cases where an individual makes a choice because of perceived socioeconomic constraints or psychological barriers [20,36]. Allan, Autin, and Duffy [20] showed that the level of perception of work as being meaningful is positively correlated with the individual's level of socioeconomic perception. In addition, they demonstrated that the group at the above-average socioeconomic level had a significantly higher perception of the meaning of work than the group at the below average socioeconomic level. Therefore, socioeconomic constraints perceived by job seekers can have a negative effect on job-seeking decisions based on self-determination. Therefore, this study assumed that job seekers' perceived socioeconomic constraints would have a negative effect on the meaning of work. However, recently, the concept of work volition has been proposed as an individual's perception in the social and economic context based on self-determination theory and as a career ability to overcome these limitations [37].

Duffy, Diemer, Perry, Laurenzi and Torrey [38] define work volition as the ability of workers to perceive themselves as capable of making professional decisions on their own despite the perceived socioeconomic constraints based on the concept presented by Blustein [39]. According to Duffy, Diemer, and Jadidian [19], there are more people who do not have the jobs they most want. However, it is important to consider how powerful decisions can be made due to the influence of inner forces when choosing a job. This is the source of control over one's needs in the future [19].

Duffy, Diemer, Perry, et al. [38] define work volition as "the ability to make full occupational decisions despite constraints." People with high levels of work volition think that even with socioeconomic constraints, there are potentially many career opportunities for them. These people believe that they can overcome the factors that hinder their opportunistic choices [23]. On the other hand, people with a low level of work volition feel that the range of jobs they can choose is narrow. Despite personal preferences that an individual has in mind, that individual is under pressure to make career choices against them [40]. Therefore, in relationships where perceived socioeconomic constraints negatively affect the meaning of work, work volition will have a positive mediating effect on the meaning of work. Based on the discussion above, the hypotheses of this study are as follows:

Hypothesis 1 (H1). Work volition will have a significant positive mediating effect, and perceived socioeconomic constraints will have a negative effect, on the meaning of work.

\subsection{The Relationship of Variables in Terms of Circumscription and Compromise Theory}

In South Korea, after the introduction of neoliberalism, the problem of rapid competition and income inequality between classes intensified. As a result, a person's occupation became an official way to confirm his or her social status [41]. In addition, the COVID-19 pandemic and the Fourth Industrial Revolution affects the world of work unpredictably [10,42]. In this environment, most job seekers have to compromise with 
their personal preferences due to real life circumstances and perceived socioeconomic constraints [39,43]. According to circumscription and compromise theory, a reality is more important than an ideal in job selection. Therefore, circumscription and compromise theory describes a career decision-making process as something that people perceive realistically in the context of social development. According to this theory, the purpose of a career choice is primarily social self-realization such as achieving a certain status or social recognition, and psychological self-realization [44]. In other words, an individual's intrinsic and psychological factors, such as personal interests and values, are limited by social factors such as social status. Gottfredson [21,22] also noticed that as children grow, they achieve a higher level of mental maturity. This process goes through four stages and intensifies in the final stage of adolescence, when career choices that individuals can make are greatly reduced. Therefore, during the four stages of becoming an adult, people realize the possibility of failing to select a job or workplace they want and give up the standards of career selection in the following order: occupational interests $\rightarrow$ social status $\rightarrow$ gender roles. While contemplating realistically selectable conditions, they attempt to give up and compromise [45].

According to Gottfredson's theory [21,22], it is important to recognize the importance of compromise rather than circumscription at the final stage. In other words, instead of pursuing ideal conditions, realistically selectable alternatives should be evaluated one by one. Then, it is more reasonable to give up lower priorities. This process of career compromise emphasizes that judgments made based on the perception of reality must be considered prior to essential elements of a profession, such as aptitudes and interests [46]. An important variable in the process of job selection leading to circumscription and compromise is how job seekers' occupational aspirations match. In other words, the matter of whether job seekers are expected to be able to have a desired job or an available job is important. This judgment becomes an important criterion in the final career selection stage.

According to previous studies in South Korea, when college students make important career selection decisions, there are two major variables that moderate or mediate their decision making. The first is a psychological variable of self-efficacy [47]. The second is the academic achievement variable that can be verified objectively [48]. When it comes to career decision-making, subjective and objective factors should be considered together. According to previous studies in South Korea, students with high levels of self-efficacy and academic achievement strive to solve problems with more sincerity and persistence. In addition, various successful experiences are accumulated in this process [49]. Similar results were found in a study of 456 Italian students [50]. Therefore, self-efficacy and academic performance reinforce the belief that one is competent in a situation where social and economic constraints are perceived, so that one can pursue a higher social position. Therefore, both variables can force an individual to limit or give up the meaning of work and make a substandard job choice. In this study, work volition-a leading variable of the meaning of work-is defined as the ability to overcome perceived social constraints and make full occupational choices. Therefore, a high level of self-efficacy and academic performance is expected to negatively moderate the relationship between perceived socioeconomic constraints and work volition.

Therefore, this study assumed that the two variables should be joint moderating variables that simultaneously moderate the relationship between perceived socioeconomic constraints and work volition (as set in Hypothesis 2). Female college students looking for a job were the subjects of this study. According to circumscription and compromise theory, these students were in the final stages of finding a job that could be adapted to realistic conditions. Thus, due to perceived socioeconomic constraints, students were first more likely to give up their career related interests such as the meaning of work, as predicted by the occupational interests-social status-gender roles continuum discussed above [45]. This abandonment is not due to the influence of self-determination. On the contrary, it is reasonable to view job seeker's conditions and circumstances as the result of circumscription and compromises. In addition, job seekers feel that they lose control 
over job choices. Moreover, external factors can weaken work volition, which is the basis of complete self-determination [39,51]. Therefore, in spite of the COVID-19 pandemic, in the research model based on the first hypothesis of this study, it is expected that selfefficacy, as a psychological factor, and academic performance, as an objective factor, will simultaneously negatively moderate work volition. Based on the discussion above, the hypotheses of this study are as follows:

Hypothesis 2 (H2). In the relationship between perceived socioeconomic constraints and the meaning of work, self-efficacy and academic performance, in a state where work volition is mediated, will have a significant negative mediated dual moderating effect.

Based on the above analysis and hypotheses, the theoretical model is established, which is shown in Figure 1.

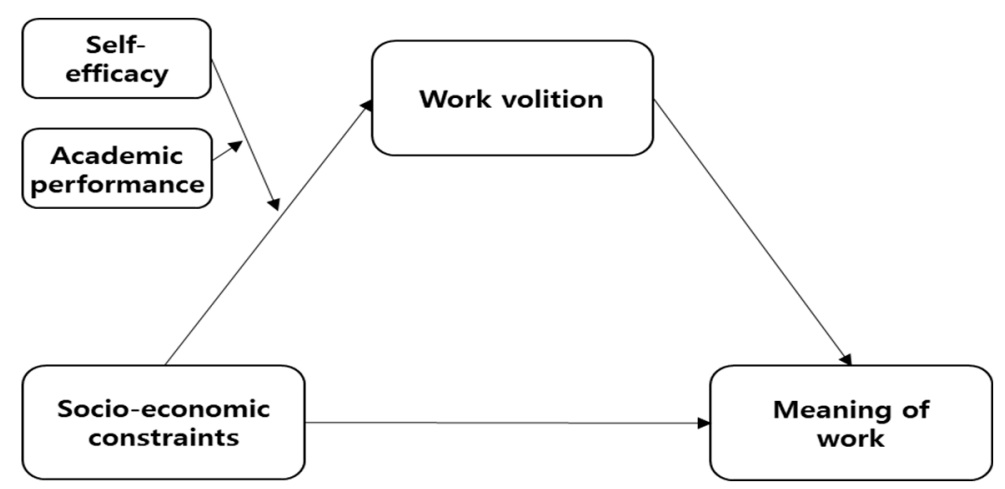

Figure 1. Theoretical model.

Figure 1 presents the research model of this study used to verify the hypotheses set above. The research model aims to confirm the mediating effect of work volition and the mediated joint moderating effect of self-efficacy and academic performance in the context where perceived socioeconomic constraints have a negative effect on the meaning of work. This study uses the methods of mediation, moderation, and conditional process analysis proposed by Hayes [52]. In the control effect test proposed by Baron and Kenny [53], there is a normality assumption, and a type 1 error may occur. In addition, if the size of the investigated sample is small and there is a high possibility of violating the normal distribution ( $t$ distribution), mediation effect verification may not be performed properly [52]. In addition, it is difficult to use the existing hierarchical regression analysis method when it is necessary to perform the analysis by combining mediating and moderating effects, or to analyze the effects of the moderating variables. Thus, Heyes [52] introduced a macro that can be used to analyze the mediated moderating effect, the moderated mediating effect, and the dual moderating effect, which makes it relatively easy to analyze complex models in which multiple variables are inputted simultaneously [52].

\section{Methodology}

\subsection{Participants and Method of Analysis}

The participants in this study were female college students. Casual sampling was used to recruit the participants. The participants completed self-report questionnaires for the Department of Secretarial Studies of College A in Incheon Metropolitan City, South Korea. The participants entered college with clear employment goals. In addition, at the time of the completion of the questionnaire, we assumed they were suitable to participate in this study because they were looking for employment in the COVID-19 pandemic situation.

A total of 198 self-report questionnaires were distributed to the participants from 4 March 2020 to 6 March 2020. We explained the background and purpose of the study to the participants and collected the completed questionnaires. In total, 198 completed questionnaires were collected. Among them, 151 questionnaires were used for data analysis. 
Forty-seven questionnaires, which had blank spaces or lacked sincerity, were excluded from the data analysis. All the participants in this study were women. The participants' average age was 20.8 years. Data coding and data cleaning processes were completed by using Excel, and validity, reliability, and correlation analyses were performed by using SPSS 20.0. The process proposed by Baron and Kenny [53] and jamovi 1.0.0 statistical software were utilized to verify the mediation effect. In addition, we used the PROCESS Macro proposed by Hayes [54] to analyze the mediated moderating effect.

\subsection{Measurements}

Socioeconomic constraints and work volition questions were revised and complemented by Kim and Lee [40] based on the Work Volition Scale-Student Version (WVS-SV) developed by Duffy, Diemer, and Jadidian [19]. We used modifications to better suit the participants of this study. The WVS-SV is composed of questions that can measure socioeconomic constraints and work volition. It has been used in several studies in South Korea and has been adapted to South Korea's situation [40]. The meaning of work was measured by modifying and supplementing the questions corrected by Kim [49] and Steger et al. [7] in the Working as Meaning Inventory (WAMI). The measurement of self-efficacy was based on Bandura's [55] theory of self-efficacy. The measurement was modified and supplemented by Hong [56], who used the self-efficacy scale developed by Sherer, Maddux, Mercandante, Prentice-Dunn, and Jacobs [57]. Lastly, academic achievement was measured based on the participants' average rating and their level of recognition. The average grade of 3.0 of all grades was set as normal.

\subsection{Analysis}

In order to measure the validity of questions for measuring the variables in this study, we conducted an exploratory factor analysis to find common factors and use them as variables. The varimax method was used to clarify the relationships among factors. Finally, the factors with an eigenvalue of 1 or higher and factor loadings of 0.5 or higher were used. We extracted 25 questions from a total of 32 questions, and four factors with an eigenvalue of 1 or more. The total accumulated variance ratio was $60.6 \%$.

Next, a reliability analysis on the final derivation items of each factor of the variables was performed. Cronbach's $\alpha$ was used as the reliability coefficient. As a result of the reliability test, the reliability coefficient for all sub-variants was found to be 0.7 or higher, which was judged to ensure reliability [58].

The average values of the main variables were $3.30(\sigma=0.73)$ for self-efficacy, 3.39 $(\sigma=0.65)$ for work volition, $3.59(\sigma=0.69)$ for work meaning, and $2.77(\sigma=0.69)$ for socioeconomic constraints. In addition, on the nominal scale, students' favorite occupations were classified into (a) secretary, (b) office worker, and (c) other. The office worker occupation had the average response value. In addition, when the average grade of 3.0 of all grades was set to the level of normal ( 3 points), the result of responding to the statement "My academic performance was not excellent" was found ( $\mathrm{M}=2.29, \sigma=1.13)$.

The correlations between the main variables that could help deduce the significance of the hypotheses in this study were as follows. First, socioeconomic constraints included work volition $(\mathrm{r}=-0.369, p<0.01)$, meaning of work $(\mathrm{r}=-0.344, p<0.01)$, self-efficacy $(\mathrm{r}=-0.400, p<0.01)$ and a significant negative relationship. These results suggest that work volition may have a mediating effect in relation to the perceived socioeconomic constraints, significantly affecting the meaning of work. In addition, self-efficacy used as a moderating variable, was found to have a significant positive relationship with work volition $(\mathrm{r}=0.567$, $p<0.01)$ and the meaning of work $(r=0.589, p<0.01)$. There was a significant negative relationship with perceived socioeconomic constraints $(r=-0.400, p<0.01)$. Moreover, academic performance used as an additional moderating variable had a significant positive relationship only with the desired occupational field $(r=0.395, p<0.001)$. In this study, additional analysis was performed based on the correlation analysis results (Table 1). 
Table 1. Correlation analysis.

\begin{tabular}{|c|c|c|c|c|c|c|c|}
\hline Variable & $M$ & $S D$ & Self-Efficacy & $\begin{array}{c}\text { Work } \\
\text { Volition }\end{array}$ & $\begin{array}{l}\text { Meaning of } \\
\text { Work }\end{array}$ & $\begin{array}{l}\text { Socioeconomic } \\
\text { Constraints }\end{array}$ & $\begin{array}{c}\text { Preferred } \\
\text { Job }\end{array}$ \\
\hline Self-efficacy & 3.30 & 0.73 & & & & & \\
\hline Work volition & 3.39 & 0.65 & $0.567^{* *}$ & & & & \\
\hline Meaning of work & 3.58 & 0.69 & $0.589 * *$ & $0.493^{* *}$ & & & \\
\hline $\begin{array}{l}\text { Socioeconomic } \\
\text { constraints }\end{array}$ & 2.77 & 0.69 & $0.400^{* *}$ & $0.368^{* *}$ & $0.344^{* *}$ & & \\
\hline Preferred job & 2.05 & 1.41 & -0.022 & 0.069 & 0.044 & 0.029 & \\
\hline Grade & 1.68 & 0.49 & 0.77 & 0.075 & 0.008 & -0.137 & -0.172 \\
\hline
\end{tabular}

Note. ${ }^{* *} p<0.01$.

\section{Results}

4.1. Mediating Effect of Work Volition on Work in Relation to Perceived Socioeconomic Constraints and the Meaning of Work

To confirm that work volition will have a significant positive mediating effect, and perceived socioeconomic constraints will have a negative effect, on the meaning of work, as expressed in hypothesis 1 of this study, the hierarchical regression analysis proposed by Baron and Kenny [53] was performed. The bootstrapping method was used to verify the statistical significance level for the indirect effect size of the mediation model. The number of samples re-extracted by bootstrapping was set to 1000 and the significance level was set to 0.05 . The results of mediating effects are shown in Tables 2 and 3 .

Table 2. Results of mediating effect analysis.

\begin{tabular}{cccccc}
\hline Effect & Label & Estimate & $S E$ & $Z$ & $p$ \\
\hline Indirect effect & $\mathrm{a} \times \mathrm{b}$ & -0.200 & 0.068 & -2.94 & 0.003 \\
Direct effect & $\mathrm{C}$ & -0.230 & 0.113 & -2.02 & 0.044 \\
Total effect & $\mathrm{c}+\mathrm{a} \times \mathrm{b}$ & -0.429 & 0.107 & -4.01 & 0.001 \\
\hline
\end{tabular}

Table 3. Route estimation result.

\begin{tabular}{cccccc}
\hline Route & Label & Estimate & $S E$ & $Z$ & $p$ \\
\hline $\begin{array}{c}\text { Perceived socioeconomic } \\
\text { constraints } \rightarrow \text { Work volition }\end{array}$ & $\mathrm{a}$ & -0.486 & 0.096 & -5.04 & 0.001 \\
$\begin{array}{c}\text { Work volition } \rightarrow \text { Meaning of work } \\
\text { Perceived socioeconomic }\end{array}$ & $\mathrm{b}$ & 0.411 & 0.113 & 3.64 & 0.001 \\
$\begin{array}{c}\text { constraints } \rightarrow \text { Meaning of work } \\
\text { M }\end{array}$ & $\mathrm{c}$ & -0.230 & 0.113 & -2.02 & 0.044 \\
\hline
\end{tabular}

The results of confirming the effect of perceived socioeconomic constraints on the meaning of work were as follows: the direct effect $(c)=-0.230, p<0.05$; the indirect effect $(\mathrm{ab})=-0.068, p<0.05$; and the total effect $(\mathrm{c}+\mathrm{ab})=-0.429, p<0.001$. The significant negative effect of perceived socioeconomic constraints on work volition was a $=-0.486$, $p<0.001$, and the significant positive effect of work volition on the meaning of work was $\mathrm{b}=0.411, p<0.001$. According to these results, $\mathrm{c}$ was greater than $\mathrm{a}$, while the significant negative effect of socioeconomic constraint on the meaning of work was $c=0.230, p<0.05$. Work volition had a partial mediating effect.

These results suggested the higher the perceived level of socioeconomic constraints, the lower the level of meaning of work. However, in this relationship, work volition had a partial mediating effect, thereby increasing the level of meaning of work. The first hypothesis of this study stated that in the relationship between perceived socioeconomic constraints and the meaning of work, self-efficacy, and academic performance in a state where work volition is mediated will have a significant negative mediated dual moderating effect. Based on these results discussed above, the first hypothesis was supported. 


\subsection{Mediated Dual Moderating Effect of Self-Efficacy and Academic Performance}

The second hypothesis in this study states that, in the relationship between perceived socioeconomic constraints and the meaning of work, self-efficacy and academic performance, in a situation where work volition is mediated, will have a significant negative mediated dual moderating effect. To verify this, we conducted an analysis by using Model 11 of SPSS PROCESS Macro suggested by Hayes [52]. The results of the analysis are shown in Table 4.

Table 4. Analysis of mediated dual moderating effect.

\begin{tabular}{|c|c|c|c|c|c|c|c|c|}
\hline DV & Variable & $B$ & $t$ & $L L C I$ & $U L C I$ & $R$ & $R 2$ & $F$ \\
\hline \multirow{10}{*}{$\begin{array}{c}\text { Work } \\
\text { volition }\end{array}$} & Constant & -2.537 & -0.990 & -7.644 & 2.569 & \multirow{10}{*}{0.679} & \multirow{10}{*}{0.461} & \multirow{10}{*}{6.856} \\
\hline & Grade & 0.078 & 0.632 & -0.168 & 0.324 & & & \\
\hline & Preferred job & 0.056 & 1.280 & -0.031 & 0.144 & & & \\
\hline & Socioeconomic constraints & 1.394 & 1.641 & -0.298 & 3.087 & & & \\
\hline & Self-efficacy (b) & 1.880 & $2.837 * *$ & 0.559 & 3.201 & & & \\
\hline & $\mathrm{a} \times \mathrm{b}$ & -0.481 & $-2.092 *$ & -0.939 & -0.022 & & & \\
\hline & Academic performance (c) & 1.590 & 1.506 & -0.514 & 3.695 & & & \\
\hline & $\mathrm{a} \times \mathrm{c}$ & -4.927 & -1.457 & -1.166 & 0.1811 & & & \\
\hline & $\mathrm{b} \times \mathrm{c}$ & -0.454 & $-1.747+$ & -0.973 & 0.064 & & & \\
\hline & $\mathrm{a} \times \mathrm{b} \times \mathrm{c}$ & 0.056 & 1.280 & -0.031 & 0.144 & & & \\
\hline \multirow{5}{*}{$\begin{array}{c}\text { Meaning of } \\
\text { work }\end{array}$} & Constant & 2.815 & $4.344^{* *}$ & 1.524 & 4.105 & \multirow{5}{*}{0.528} & \multirow{5}{*}{0.279} & \multirow{5}{*}{7.459} \\
\hline & Grade & -0.026 & -0.189 & -0.298 & 0.246 & & & \\
\hline & Preferred job & 0.005 & 0.123 & -0.089 & 0.101 & & & \\
\hline & Socioeconomic constraints & -0.228 & $-1.943 *$ & -0.462 & 0.005 & & & \\
\hline & Work volition & 0.412 & $3.486^{* *}$ & 0.176 & 0.648 & & & \\
\hline
\end{tabular}

As a result of the analysis, the effect of perceived socioeconomic constraints on work volition was not significant. Therefore, the second hypothesis was rejected. However, the significance of the second hypothesis verification process is as follows. First, self-efficacy injected as a control variable increased the work volition level $(\mathrm{B}=1.880, p<0.01)$, and the interaction terms $(\mathrm{a} \times \mathrm{b})$ between the perceived socioeconomic constraints $(\mathrm{a})$ and selfefficacy(b)were significant. It was shown that it had a negative effect on volition. These results do not support the hypothesis suggested by the theoretical background. However, self-efficacy had a significant positive effect on work volition. At this time, the perceived socio-economic constraints combined with self-efficacy showed a pure moderating effect that had a significant negative effect. In addition, the interaction variable between selfefficacy and academic performance was an independent variable, which was found to have a significant negative effect on work volition $(\mathrm{B}=-0.454, p<0.10)$.

\section{Implications and Conclusions}

In the COVID-19 pandemic, this study presented somewhat contradictory aspects of self-determination, and circumscription and compromise theory in order to confirm whether the meaning of work is an important aspect of job searching and employment in the context of job seekers' awareness of socioeconomic constraints. In addition, one of the goals of this study was to identify the mediating effect of work volition in the relationship between perceived socioeconomic constraints and the meaning of work. In addition, by exploring the situation and related variables in which work volition is moderated in the negative direction, this study attempted to find practical implications that can be used for personnel management by South Korean and global companies. The theoretical implications of this study are presented below.

\subsection{Implications}

First, in the COVID-19 pandemic, it was confirmed that perceived socioeconomic constraints—-the independent variable in this study—have a negative effect on the meaning 
of work - the dependent variable. In addition, work volition has a significant positive partial mediating effect in the relationship between the two variables. These results confirm that socioeconomic constraints perceived by job seekers in the COVID-19 pandemic can violate the subjectivity of job choices, such as the meaning of work. In addition, it was confirmed that even if socioeconomic constraints were recognized, people with high work volition levels still wanted to pursue meaning in their work. Above all, work volition can be a psychological core driver for job seekers to overcome various disadvantages and engage in their desired work. This study's theoretical significance is derived from the proof of this effect, which is found in the results of this study.

Second, in the relationship between perceived socioeconomic constraints and the meaning of work, the mediated dual moderating effect of self-efficacy and academic performance, in the situation where work volition was mediated, was not confirmed. However, it was confirmed that self-efficacy used as a moderating variable significantly increased the level of work volition, and that the interaction effect of perceived socioeconomic constraints and self-efficacy had a significant negative effect on work volition. In addition, it was also confirmed that the interaction effect between self-efficacy and academic performance had a significant negative effect on work volition.

Although the main hypothesis was rejected, these results could have the following theoretical implications. First, this study revealed that perceived socioeconomic constraints have a negative effect on work volition, but self-efficacy has a positive effect on work volition. Similar results were also found in a study of 80 Italian students [59]. An outcome that an individual expects is determined by his or her judgment on how well he or she can perform in a situation $[60,61]$. Mastery experiences, vicarious experiences, and verbal persuasion act as important grounds for self-judgment [60]. Therefore, a high level of self-efficacy in this study increased the level of work volition. The participants of this study had mastery experiences related to job searching (e.g., passing a document screening), vicarious experiences (e.g., successful employment of a classmate who was in a position similar to them), and were subjected to verbal persuasion (e.g., advice and counseling by a professor). Therefore, it can be suggested that the level of work volition can be increased by job seekers' participation in related activities, counseling, and programs centered on their job search.

Third, the interaction effect between self-efficacy and academic performance was found to have a significant negative effect on work volition. These results suggest that if the level of self-efficacy is high and the level of academic performance is high, the level of work volition may be lowered. These students are often called exemplary students at school. According to Bandura [60], a person with a high level of self-efficacy tends to prepare for an unexpected situation by paying more attention and effort to his or her situation. In this study, if the participants were aware of their socioeconomic constraints such as a poor financial situation in the COVID-19 pandemic, they would try to meet the job search criteria desired by society or a specific company rather than the job search criteria they wanted. A number of career and employment-related studies in South Korea suggested that job searching that reflects psychological factors that job seekers consider important, such as interests and values, ultimately has a significant impact on individual self-realization and happiness [62]. However, in the COVID-19 pandemic situation, when college students with high levels of self-efficacy and academic achievement face a job search problem that needs to be solved, it is possible for them to make decisions in a way that compromises with the job search problem they face $[63,64]$. In South Korea, there has been little research on this. Therefore, this study has a theoretical significance in that it demonstrates a psychological phenomenon of the job seekers' decision-making process and their circumscription and compromise tendencies.

Based on these results, one of the groups expected to be able to obtain a job with high social status, high salary and welfare benefits is the one with high self-efficacy and academic performance. Therefore, from the perspective of circumscription and compromise theory, one aspect of an individual's strong job searching motivation is social status [65]. 
Therefore, in spite of the COVID-19 pandemic situation, it is important for companies to verify applicants' values during the recruitment process. It is necessary to check the specific content of a social position that job seekers want to obtain as a result of being employed by a company. In general, companies manifest a social position to job seekers in the form of a compensation and welfare package. It is important for job seekers to check information about companies to ensure authenticity and openness in the recruitment and job searching processes and to compensate for any gaps in information provided by the companies.

\subsection{Limitations}

In a situation where the pursuit of meaning of work has received a lot of interest in South Korea, this study asked if job searching was a result of self-determination or if it was a result of a circumscription and compromise process. This study sought to present an opposing view of self-determination theory, and circumscription and compromise theory, and to expand the discussion on job searching and recruitment from a practical point of view. It confirmed that although job seekers were aware of socio-economic constraints, those with a high level of work volition could seek meaningful work. Furthermore, if the negative dual moderating effect of self-efficacy and academic achievement was rejected, decisions based on self-determination theory could be supported more when people look for a job. However, if supported, it was expected that job searching decisions based on circumscription and compromise theory could be supported more.

The results of this study give a glimpse into the psychology of people who are currently looking for jobs in South Korea. According to the results of this study, only job seekers' psychology was supported from the perspective of self-determination theory. According to these results, the assumption that job searching is a result of self-determination is more convincing. In other words, work volition, a key variable of self-determination, should be refined in a job searching situation and is subject to verification in an employment situation.

However, there is a problem with generalizability of the results of this study because it was limited to a specific group of college students in South Korea. In addition, all the research participants were women. Thus, the participants were not representative of the general population. In future studies, a more representative sample should be obtained, and both genders should be used as main variables to determine whether work volition and the meaning of work differ according to gender.

\subsection{Conclusions}

The meaning of work is connected to the happiness of life and the achievement of higher needs from the viewpoint of putting the psychology of the job seeker as important. Therefore, the meaning of work can be an important variable for job seekers in the COVID19 pandemic situation. Additionally, the meaning of work is important from the standpoint of corporate personnel management. Hiring people who want to find meaning and rewards in their work can have a positive impact on corporate performance in the long run. In this context, this study judged work volition as an antecedent variable that affects the meaning of work. It was also judged as a variable that could have a mediating effect in the relationship between perceived socioeconomic constraints and the meaning of work. Specifically, from the standpoint of SDT, since a high level of work volition has a positive effect on the meaning of work, the researchers of this study tried to emphasize the importance of the work volition variable in both job searching and recruitment. In addition, from the viewpoint of Gottfredson's theory, an exploration of the effects of negative influence on the level of meaning of work was attempted by moderating the work volition level in the negative direction while being aware of the socioeconomic constraints of the COVID-19 pandemic.

According to the results of this study, people with high work volition levels are likely to find jobs that reflect their beliefs and values even though they are aware of socioeconomic constraints. In addition, according to previous studies, people who look for meaning in their work often work for a long time in their fields, feel rewarded and help to improve 
the performance of a company $[33,66,67]$. This effect is similarly seen not only in general companies but also in fields such as medical care [68], welfare [69], education [70], and religion [71]. Therefore, when hiring, it is important for companies to check work volition, which is a leading factor in the meaning of work. In other words, it will be important to determine how strong the applicant's willingness to make professional decisions is based on his or her job values, aptitude, and interests in recruiting and selecting new personnel. In addition, job seekers will have to accumulate success experiences in the job preparation process, actively participate in related programs, and receive advice in order to increase self-efficacy in their job search [72]. Furthermore, companies need to see more closely what volunteers have been trying to find and how they have discovered their potential for development and potential [73].

Finally, the practical limitations of this study and suggestions for future study are as follows.

First, the significant results of the mediated biphasic regulation effect between selfefficacy and academic performance, which were the core hypotheses of this study, were not confirmed. According to these results, the assertion that the "job search is limited - the result of compromise" proposed in the title of this paper was not supported. Furthermore, the analysis of the cause of such a result is as follows.

The analysis of the regulation effect of $<$ Table $4>$ for verifying hypothesis 2 shows that the $\mathrm{t}$-value of " $\mathrm{a} \times \mathrm{b} \times \mathrm{c}$ ", an interactive term for perceived socio-economic constraints (a), self-efficacy (b), and academic performance (c), was 1.280 (level of significance for $\mathrm{t}$ : $p<0.05$ to $t>1.96$ ). Since $t$ is the value obtained by dividing the standard error by the regression coefficient, the smaller the standard error, the larger the $t$ value. Therefore, as the sample size increases, the t-value may increase. In verifying hypothesis 2 of this study, there may be various causes for the fact that the $t$-value of an interactive term for verifying the biphasic regulation effect did not reach the level of 1.96; the main reasons are that the research subject was limited to students of a specific university and that the number of sampled questionnaires was not large, which are considered to be the key reasons that the hypothesis has not been verified. After all, the larger $t$-value means that the standard deviation is small. Therefore, it is necessary to supplement the issues that occurred in this study through more sampling in future studies.

In addition, the fact that the subject of study was limited to female students from a specific university indicates that gender type is one of the factors of career compromise, so there should be consideration for gender types in subsequent studies. Although some studies have reported that it is not significant to consider gender types in career choices, unlike Gottfredson's [22] early theory, the lack of consideration of gender in the context of restriction-compromise theory is a clear limitation of this work. In future studies, it is necessary to secure more research subjects and inject gender types as the main variables to determine whether major variables such as free will of work and significance of work differ depending on gender types.

Second, although self-efficacy was suggested as an antecedent factor of work volition in this study, it is necessary to clarify what is the antecedent factor of work volition, which is a key variable of self-determination, through more detailed literature and precedent study. There is still a lack of a model that has been confirmed by inputting the pre- and post-variables related to the underlying theory that can explain the relationship between the work volition and the variables that affect the significance of work.

Third, this study also has limitations of not being able to utilize the big data of the university to which the subjects belong. In future research, it is also necessary to utilize big data such as vocational aptitude tests and psychological assessments conducted on job seekers at universities. It is believed that universities can find ways to improve the quantitative and qualitative results of employment by analyzing the relationship between the rate of participation in the job search program and the level of work volition during enrollment, and the correlation between the graduate's retained employment rate and job satisfaction. In addition, it is necessary for companies to analyze the relationship between 
the work volition at the beginning of employment and the significance of work perceived after employment, and the resulting job satisfaction or the relationship with changing jobs. This could also help companies find a deeper understanding of human resource management factors and the impact analyzed implications can have on organizational performance in the long term.

Author Contributions: The authors contributed equally to this work. All the authors contributed to the conceptualization, formal analysis, investigation, methodology, writing of the original draft, and review and editing. All authors have read and agreed to the published version of the manuscript.

Funding: This research received no external funding.

Institutional Review Board Statement: Ethical review and approval were waived for this study because although it was a human study, it was observational, and the research design did not involve ethical issues.

Informed Consent Statement: Informed consent was obtained from all subjects involved in the study.

Data Availability Statement: Data sharing not applicable. The data are not publicly available due to participants' privacy.

Conflicts of Interest: The authors declare no conflict of interest.

\section{References}

1. Kramer, A.; Kramer, K.Z. The Potential Impact of the Covid-19 Pandemic on Occupational Status, Work from Home, and Occupational Mobility; Elsevier: Amsterdam, The Netherlands, 2020.

2. Schnell, T.; Höge, T.; Pollet, E. Predicting meaning in work: Theory, data, implications. J. Posit. Psychol. 2013, 8, 543-554. [CrossRef]

3. Seo, A.R.; Jung, Y.S.; Sohn, Y.W. The influence of job crafting and task identity on meaningful work: The moderated mediating effect of perceived organizational support. Korean J. Ind. Organ. Psychol. 2018, 31, 149-173. [CrossRef]

4. Park, Y.; Lim, D.H.; Kim, W.; Kang, H. Organizational Support and Adaptive Performance: The Revolving Structural Relationships between Job Crafting, Work Engagement, and Adaptive Performance. Sustainability 2020, 12, 4872. [CrossRef]

5. Kim, K.M.; Ryu, S.A. Positive emotion, satisfaction with college life, and career preparation: The mediation of calling. Korean J. Cult. Soc. Issues 2019, 25, 231-248. [CrossRef]

6. Hwang, M.H.; Cho, H.J.; Cho, Y.J.; Bang, J.W. A qualitative study on the meaning of work and experiences of career decision process of university students. Korean J. Psychol. Gen. 2013, 32, 675-699.

7. Steger, M.F.; Dik, B.J.; Duffy, R.D. Measuring Meaningful Work:The Work and Meaning Inventory (WAMI). J. Career Assess. 2012, 20, 322-337. [CrossRef]

8. Wrzesniewski, A.; Dutton, J.E. Crafting a job: Revisioning employees as active crafters of their work. Acad. Manag. Rev. 2001, 26, 179-201. [CrossRef]

9. donaA.com. Available online: https:/ / www.donga.com/news/Economy/article/all/20200116/99247661/1 (accessed on 16 January 2020).

10. Aristovnik, A.; Keržič, D.; Ravšelj, D.; Tomaževič, N.; Umek, L. Impacts of the COVID-19 pandemic on life of higher education students: A global perspective. Sustainability 2020, 12, 8438. [CrossRef]

11. Parola, A. Novel coronavirus outbreak and career development: A narrative approach into the meaning for Italian University Graduates. Front. Psychol. 2020, 11, 2255. [CrossRef]

12. Gautam, S.; Hens, L. COVID-19: Impact by and on the Environment, Health and Economy; Springer: Berlin/Heidelberg, Germany, 2020.

13. Pratt, M.G.; Ashforth, B.E. Fostering meaningfulness in working and at work. Posit. Organ. Scholarsh. Found. New Discip. 2003, $309,327$.

14. Guichard, J. Career guidance, education, and dialogues for a fair and sustainable human development. In Proceedings of the Inaugural Conference of the UNESCO Chair of Lifelong Guidance and Counselling. University of Wroclaw, Wrocław, Poland, 6-27 November 2013.

15. Blustein, D. The Psychology of Working: A New Perspective for Career Development, Counseling, and Public Policy; Routledge: England, UK, 2013. [CrossRef]

16. Al-Youbi, A.O.; Al-Hayani, A.; Rizwan, A.; Choudhry, H.J.S. Implications of COVID-19 on the Labor Market of Saudi Arabia: The Role of Universities for a Sustainable Workforce. Sustainability 2020, 12, 7090. [CrossRef]

17. Pullano, G.; Valdano, E.; Scarpa, N.; Rubrichi, S.; Colizza, V. Evaluating the effect of demographic factors, socioeconomic factors, and risk aversion on mobility during the COVID-19 epidemic in France under lockdown: A population-based study. Lancet Digit. Health 2020, 2, e638-e649. [CrossRef]

18. Martin, A.; Markhvida, M.; Hallegatte, S.; Walsh, B. Socio-economic impacts of COVID-19 on household consumption and poverty. Econ. Disasters Clim. Chang. 2020, 4, 453-479. [CrossRef] [PubMed] 
19. Duffy, R.D.; Diemer, M.A.; Jadidian, A. The Development and Initial Validation of the Work Volition Scale-Student Version. Couns. Psychol. 2012, 40, 291-319. [CrossRef]

20. Allan, B.A.; Autin, K.L.; Duffy, R.D. Examining Social Class and Work Meaning Within the Psychology of Working Framework. J. Career Assess. 2014, 22, 543-561. [CrossRef]

21. Gottfredson, L.S. Circumscription and compromise: A developmental theory of occupational aspirations. J. Couns. Psychol. 1981, 28, 545-579. [CrossRef]

22. Gottfredson, L.S. Gottfredson's theory of circumscription and compromise. In Career Choice Development; Routledge: England, UK, 1996; pp. 179-232.

23. Ahn, J.A. The relationship among social class, academic prestige related constraints, and decent work: The mediating effects of work volition and career adaptability. Korea J. Couns. 2019, 20, 133-153. [CrossRef]

24. Deci, E.L.; Ryan, R.M. Overview of self-determination theory: An organismic dialectical perspective. In Handbook of SelfDetermination Research; The University of Rochester Press: New York, NY, USA, 2002; pp. 3-33.

25. Martinent, G.; Ferrand, C.; Humblot, E.; Bauvineau, A.; Noisiez, M. Role of need-supportive family behaviours on purpose in life and depressive feelings of French older people: A self-determination theory perspective. Appl. Sci. 2019, 9, 115. [CrossRef]

26. Sicilia, A.; Águila, C.; Posse, M.; Alcaraz-lbáñez, M. Parents' and Peers' Autonomy Support and Exercise Intention for Adolescents: Integrating Social Factors from the Self-Determination Theory and the Theory of Planned Behaviour. Int. J. Environ. Res. Public Health 2020, 17, 5365. [CrossRef]

27. Baumeister, R.F.; Leary, M.R. The need to belong: Desire for interpersonal attachments as a fundamental human motivation. Psychol. Bull. 1995, 117, 497-529. [CrossRef]

28. Vansteenkiste, V.; Lens, W.; De Witte, H.; Feather, N.T. Understanding unemployed people's job search behaviour, unemployment experience and well-being: A comparison of expectancy-value theory and self-determination theory. Br. J. Soc. Psychol. 2005, 44, 269-287. [CrossRef] [PubMed]

29. Sheldon, K.M.; Elliot, A.J. Not all Personal Goals are Personal: Comparing Autonomous and Controlled Reasons for Goals as Predictors of Effort and Attainment. Personal. Soc. Psychol. Bull. 1998, 24, 546-557. [CrossRef]

30. Rosso, B.D.; Dekas, K.H.; Wrzesniewski, A. On the meaning of work: A theoretical integration and review. Res. Organ. Behav. 2010, 30, 91-127. [CrossRef]

31. Ren, T.; Cao, L.; Chin, T.; Health, P. Crafting Jobs for Occupational Satisfaction and Innovation among Manufacturing Workers Facing the COVID-19 Crisis. Int. J. Environ. Res. Public Health 2020, 17, 3953. [CrossRef] [PubMed]

32. Kashdan, T.B.; Steger, M.F. Curiosity and pathways to well-being and meaning in life: Traits, states, and everyday behaviors. Motiv. Emot. 2007, 31, 159-173. [CrossRef]

33. Duffy, R.D.; Allan, B.A.; Autin, K.L.; Bott, E.M. Calling and life satisfaction: It's not about having it, it's about living it. J. Couns. Psychol. 2013, 60, 42-52. [CrossRef]

34. Blustein, D.L. Extending the Reach of Vocational Psychology: Toward an Inclusive and Integrative Psychology of Working. J. Vocat. Behav. 2001, 59, 171-182. [CrossRef]

35. Brown, D.; Brooks, L. Career Counseling Techniques; Allyn \& Bacon: Boston, MA, USA, 1991.

36. Hsieh, H.-H.; Huang, J.-T. The Effects of Socioeconomic Status and Proactive Personality on Career Decision Self-Efficacy. Career Dev. Q. 2014, 62, 29-43. [CrossRef]

37. Duffy, R.D.; Douglass, R.P.; Autin, K.L.; Allan, B.A. Examining Predictors of Work Volition among Undergraduate Students. J. Career Assess. 2016, 24, 441-459. [CrossRef]

38. Duffy, R.D.; Diemer, M.A.; Perry, J.C.; Laurenzi, C.; Torrey, C.L. The construction and initial validation of the Work Volition Scale. J. Vocat. Behav. 2012, 80, 400-411. [CrossRef]

39. Blustein, D.L. The role of work in psychological health and well-being: A conceptual, historical, and public policy perspective. Am. Psychol. 2008, 63, 228-240. [CrossRef] [PubMed]

40. Kim, N.R.; Lee, K.H. Career volition and constraints of the college students: The Korean validation study of the Work Volition Scale? Student version (WVS-SV). J. Vocat. Educ. Res. 2014, 33, 41-58.

41. Gao, H.Y.; Kim, E.H. A review of the priority order in career compromise. Korea J. Couns. 2009, 10, 2207-2224. [CrossRef]

42. Ahn, S.H.; Lee, M.H. Fourth industrial revolution impact: How it changes jobs. Korean Acad. Soc. Bus. Adm. 2016, 8, $2344-2363$.

43. Duffy, R.D.; Dik, B.J. Beyond the Self: External Influences in the Career Development Process. Career Dev. Q. 2009, 58, 29-43. [CrossRef]

44. Luke, C.; Redekop, F.K. Gottfredson's Theory: Application of Circumscription and Compromise to Career Counseling. In Career Development across the Lifespan: Counseling for Community, Schools, Higher Education, and Beyond; Information Age Publishing: Charlotte, NC, USA, 2019; pp. 61-79.

45. Hwang, M.H. The review of empirical studies of Gottfredson's theory in Korea. J. Career Educ. Res. 2009, $22,1-17$.

46. Cochran, D.B.; Wang, E.W.; Stevenson, S.J.; Johnson, L.E.; Crews, C. Adolescent occupational aspirations: Test of Gottfredson's theory of circumscription and compromise. Career Dev. Q. 2011, 59, 412-427. [CrossRef]

47. Kim, K.W.; Jo, Y.H. Mediation and moderation effects of self-efficacy between career stress and college adjustment among freshmen. Korean J. Youth Stud. 2011, 18, 197-218.

48. Jang, K.A.; Lee, J.Y.; Kim, S.H. The relation between parental academic involvement and career-aspirations among middle school students: Testing the mediating effects of academic self- efficacy and academic achievement. J. Korean Educ. Forum 2011, 10, 1-23. 
49. Kim, Y.W.; Park, J.S.; Jeon, K.H. A study on the mediating role of the self-direction in the relationship between the self-efficacy and the academic achievement of adult learners in a cyber university. J. Educ. Inf. Media 2013, 19, 743-764.

50. Bozzato, P.J.S.S. The Relationship between Children's Aspiration Profiles and Self-Efficacy, Life Satisfaction, and Academic Achievement. Soc. Sci. 2020, 9, 77. [CrossRef]

51. Kim, N.R.; Lee, K.H. The autoregressive cross-lagged model between work volition and meaningful work. Korea J. Couns. 2019, 20, 155-174. [CrossRef]

52. Hayes, A.F. Introduction to Mediation, Moderation, and Conditional Process Analysis: A Regression-Based Approach; Guilford Publications: New York, NY, USA, 2017.

53. Baron, R.M.; Kenny, D.A. The moderator-mediator variable distinction in social psychological research: Conceptual, strategic, and statistical considerations. J. Personal. Soc. Psychol. 1986, 51, 1173-1182. [CrossRef]

54. Hayes, A.F. The Process Macro for SPSS and SAS (Version 2.13); Software: New York, NY, USA, 2016.

55. Bandura, A. Self-Self Efficacy: The Exercise of Control; Freeman: New York, NY, USA, 1997.

56. Hong, H.Y. The Relationship of Perfectionism, Self-Efficacy and Depression. Master's Thesis, E-Wha Women's University, Seoul, Korea, 1995.

57. Sherer, M.; Maddux, J.E.; Mercandante, B.; Prentice-Dunn, S.; Jacobs, B.; Rogers, R.W. The Self-Efficacy Scale: Construction and Validation. Psychol. Rep. 1982, 51, 663-671. [CrossRef]

58. Nunnally, J.C.; Bernstein, I.H. Psychometric Theory, 3rd ed.; McGraw-Hill: New York, NY, USA, 1994.

59. Zammitti, A.; Magnano, P.; Santisi, G. "Work and Surroundings": A Training to Enhance Career Curiosity, Self-Efficacy, and the Perception of Work and Decent Work in Adolescents. Sustainability 2020, 12, 6473. [CrossRef]

60. Bandura, A. Self-efficacy and health behaviour. In Cambridge Handbook of Psychology, Health Medicine; Cambridge University Press: Cambridge, UK, 1997; pp. 160-162.

61. Yoon, P.H. Team Leader's Transformational Leadership and Team Member's Personal Effectiveness. Ph.D. Thesis, Chung-Ang University, Seoul, Korea, 2013.

62. Park, G.S.; Kim, J.H. Korean male college students' gender roles and career compromise: A test of Gottfredson's (1981) theory. Korean Soc. Study Career Educ. 2009, 22, 43-61.

63. Creed, P.A.; Hughes, T. Career Development Strategies as Moderators Between Career Compromise and Career Outcomes in Emerging Adults. J. Career Dev. 2013, 40, 146-163. [CrossRef]

64. Creed, P.A.; Gagliardi, R.-E. Career Compromise, Career Distress, and Perceptions of Employability:The Moderating Roles of Social Capital and Core Self-Evaluations. J. Career Assess. 2015, 23, 20-34. [CrossRef]

65. Ng, T.W.H.; Feldman, D.C. Subjective career success: A meta-analytic review. J. Vocat. Behav. 2014, 85, 169-179. [CrossRef]

66. Hulshof, I.L.; Demerouti, E.; Le Blanc, P.M. Meaning in work as an explanatory mechanism in the relationship between job crafting, work engagement and performance: A diary study. Career Dev. Int. 2019, 25, 355-371. [CrossRef]

67. Magnano, P.; Santisi, G.; Zammitti, A.; Zarbo, R.; Di Nuovo, S. Self-perceived employability and meaningful work: The mediating role of courage on quality of life. Sustainability 2019, 11, 764. [CrossRef]

68. Gómez-Salgado, J.; Navarro-Abal, Y.; López-López, M.J.; Romero-Martín, M.; Climent-Rodríguez, J.A. Engagement, passion and meaning of work as modulating variables in nursing: A theoretical analysis. Int. J. Environ. Res. Public Health 2019, 16, 108. [CrossRef] [PubMed]

69. Vincent-Höper, S.; Lengen, J.C.; Kersten, M.; Gregersen, S. Analysis of Job-Related Demands and Resources in Ambulatory Youth Welfare Services: A Qualitative and Quantitative Approach. Int. J. Environ. Res. Public Health 2020, 17, 2941. [CrossRef] [PubMed]

70. Alonso, C.; Fernández-Salinero, S.; Topa, G. The impact of both individual and collaborative job crafting on Spanish teachers' well-being. Educ. Sci. 2019, 9, 74. [CrossRef]

71. Griebel, J.M.; Park, J.Z.; Neubert, M.J. Faith and work: An exploratory study of religious entrepreneurs. Religions 2014, 5, 780-800. [CrossRef]

72. Liu, S.; Wang, M.; Liao, H.; Shi, J. Self-regulation during job search: The opposing effects of employment self-efficacy and job search behavior self-efficacy. J. Appl. Psychol. 2014, 99, 1159. [CrossRef] [PubMed]

73. Wanberg, C.R.; Zhu, J.; van Hooft, E.A.J. The Job Search Grind: Perceived Progress, Self-Reactions, and Self-Regulation of Search Effort. Acad. Manag. Rev. 2010, 53, 788-807. [CrossRef] 